\title{
Association Analysis between SNP Marker in Neuopeptide Y (NPY) Gene and Carcass and Meat Quality Traits in Korean Cattle
}

\author{
Eui-Ryong Chung*, Sung-Chul Shin, and Jae-Pil Heo \\ Division of Animal Science and Resources, College of Life Science and Natural Resources, \\ Sangji University, Wonju 220-702, Korea
}

\begin{abstract}
Biological or physiological genes that regulate metabolism and energy partitioning have the potential to influence economically important traits such as carcass and meat quality traits in beef cattle. The neuropeptide Y (NPY) functions as a central appetite stimulator and plays a major role in feed intake and energy-balance control. Therefore, the NPY gene is an excellent biological and physiological candidate gene for body weight, feeding, fatness or growth related traits in beef cattle. The objective of this study was to identify single nucleotide polymorphisms (SNPs) in the NPY gene and to evaluate the association of NPY SNP markers with carcass and meat quality traits in Korean cattle. The genomic region (711 bp) including intron 2 of NPY gene was amplified and sequenced, and five SNPs, g.4389 Del(C), g.4371Del(C), g.4271T $>$ C, g.1899A $>\mathrm{G}$ and g.1517A $>$ C, were identified. The PCR-RFLP method was then developed to genotype the individuals examined. The g.4271T $>$ C SNP was significantly associated with M. Longissimus dori area (LDA) value $(p<0.027)$. Animals with the TT $\left(78.144 \pm 0.950 \mathrm{~cm}^{2}\right)$ genotype had higher LDA than those with the CC $\left(72.266 \pm 2.039 \mathrm{~cm}^{2}\right)$, and animals with TC genotype showed intermediate value. This SNP genotype also showed a highly significant additive genetic effect for the LDA $(p<0.01)$. No significant associations, however, was detected between any of the SNP genotype and other carcass traits measured in this study. In conclusion, SNP genotype of the NPY gene may be used as DNA markers to select animals that have a higher meat yield.
\end{abstract}

Key words: neuropeptide Y gene, single nucleotide polymorphisms marker, carcass traits, meat yield, Korean cattle

\section{Introduction}

It has been well known that variation in meat quality traits can be influenced by genetic - environmental interactions where the expression of a genetic trait, or genotypes, changes in response to the environment. In order for beef industry to consistently produce high quality meat, there must be an understanding of the genetic factors that cause carcass and meat quality traits to vary (Warner et al., 2010). Recently, the development of the field of genomics has stimulated interest in DNA markerbased selection for carcass and meat quality traits. Once a DNA marker as an indicator of economically important traits has been shown to be associated with variation in the target trait, then it can be used to genetically DNA type young animals for pre-selection before performance

\footnotetext{
*Corresponding author: Eui-Ryong Chung, Division of Animal Science and Resources, College of Life Science and Natural Resources, Sangji University, Wonju 220-702, Korea. Tel: 8233-730-0534, Fax: 82-33-744-6118, E-mail: erchung@sangji. ac.kr
}

testing (Sosnicki and Newman, 2010). The physiological regulation of carcass and meat quality traits in animals is under the control of many genes, which may be important biological candidate genes for unraveling the genetic variation in economically important traits in farm animals (Sherman et al., 2008). A number of useful gene markers that affect carcass and meat quality traits have been discovered and applied in beef cattle (Warner et al., 2010; Sosnicki and Newman, 2010). The development of DNA markers with predictive merit for beef cattle production traits has potential to have a positive impact on carcass traits. Therefore, it is of interest to identify more DNA markers of biological or physiological candidate genes and to evaluate their effects on carcass traits in beef cattle.

Neuropeptide Y (NPY) is known to be involved in the central regulation of food intake, energy homeostasis and reproductive function, and is one of the mediators of leptin as a protein expressed by adipocytes (Thue and Buchanan, 2004). NPY is highly expressed in hypothalamic of undernourished and genetically obese animals (Dyer et al., 1997). In human, it is known that the expres- 
sion and secretion of the NPY peptide in the hypothalamus are increased during depletion of body fat stores and /or reduced leptin/insulin signaling to the brain, resulting in an increased energy intake. Furthermore, deletion of the NPY gene reduces hyperphagia and obesity in $o b / o b$ mice (van Rossum et al., 2006). Recently, the polymorphisms in the bovine NPY gene was reported to be associated with growth traits such as body length and chest girth (Zhang et al., 2011). These findings indicate that NPY gene is an excellent biological candidate gene for body weight, feeding, fatness or growth related traits in human and livestock (Zhang et al., 2011). Therefore, based on the physiological and biological functions and roles of NPY in food intake, body fat deposition and obesity, the gene encoding NPY was chosen as a biological and physiological candidate gene for association tests with carcass and meat quality traits in beef cattle. The objective of this study was to identify single nucleotide polymorphisms (SNPs) of the NPY gene and to evaluate associations between SNP marker of the NPY gene and carcass and meat quality traits in Korean cattle (Hanwoo).

\section{Materials and Methods}

\section{Animals, carcass data and DNA preparation}

A total of 309 unrelated Hanwoo steers used in this study were from progeny testing program of National Livestock Research Institute (NLRI) of Korea. All steers of the national progeny-testing population were fed under the tightly controlled conditions of the feeding program. Meat samples were collected from 13th thoracic rib to the first lumbar vertebrae of the steers within $24 \mathrm{~h}$ of slaughter and evaluated by mechanical and physical methods according to the Animal Product Grading System of Korea. The carcass data analyzed were live weight (LW), carcass weight $(\mathrm{CW})$, dressing percentage (DP), backfat thickness (BF), M. Longissimus dorsi area (LDA) and marbling score (MS). BF and LDA were measured at the $12^{\text {th }}$ - and $13^{\text {th }}$-rib interface. MS for quality grade was evaluated on a cross section of the longissimus muscle at the $12^{\text {th }}$-to $13^{\text {th }}$-rib interface by official graders according to the Korean Beef Marbling Standard. MS is scored on a scale from 1 to 7 with 7 being associated with the best marbling. The mean and standard deviations for traits analyzed in this study are presented in Table 1. For each animal, genomic DNA was extracted from whole blood by using a $\mathrm{NaCl}$ precipitation protocol (Miller et al., 1988). The DNA sample was suspended in TE buffer (10 $\mathrm{mM}$ Tris-HCl, $\mathrm{pH} 7.4 ; 1 \mathrm{mM}$ EDTA) and stored at -20
Table 1. Mean, standard deviation (SD) and extreme values of phenotypic values measured on each trait in Hanwoo population $(n=309)$

\begin{tabular}{lcccc}
\hline \hline \multicolumn{1}{c}{ Traits } & Mean & SD & Minimum & Maximum \\
\hline $\mathrm{LW} / \mathrm{kg}$ & 538.22 & 51.564 & 390 & 690 \\
$\mathrm{CW} / \mathrm{kg}$ & 307.29 & 32.558 & 212 & 401 \\
$\mathrm{BF} / \mathrm{cm}$ & 0.70 & 0.30 & 0.2 & 1.8 \\
$\mathrm{EMA} / \mathrm{cm}^{2}$ & 75.466 & 8.195 & 54 & 97 \\
$\mathrm{MS} / 1 \sim 7$ & 2.35 & 1.43 & 1 & 7 \\
$\mathrm{MC} / 1 \sim 7$ & 4.819 & 0.489 & 2 & 7 \\
$\mathrm{FC} / 1 \sim 7$ & 2.99 & 0.127 & 2 & 4 \\
$\mathrm{TEX} / 1 \sim 3$ & 1.346 & 0.679 & 1 & 3 \\
\hline
\end{tabular}

LW, live weight; CW, carcass weight; $\mathrm{BF}$, backfat thickness; LDA, M. Longissimus dorsi area; MS, marbling score; MC, meat color; FC, fat color; TEX, texture

until analysis.

\section{Sequence analysis and SNP discovery}

The primers for amplification and sequencing analysis were designed based on the genomic DNA sequence of the bovine NPY gene from nucleotides and 3853-4563 of GenBank accession no. NC_007302.4 using the Primer 3 program (http://frodo.wi.mit.edu/). The sequence of primers used was Bovine-NPYF (5'-CCCCAGGGTGATTCTAACATCT-3') and Bovine-NPYR (5'-GGTGAGTGAGGACATGGTCTGT-3') and amplicon length was $711 \mathrm{bp}$. To determine SNP identification, pooled DNA samples from the sixty unrelated animals were amplified by PCR using the primer pair. The PCR amplification was performed in a DNA thermal cycler (Perkin Elmer Cetus, Norwalk, CT). The PCR reaction was performed in a 20 $\mu \mathrm{L}$ reaction mixture containing $0.1 \mu \mathrm{M}$ of each primer, $1.5 \mathrm{mM} \mathrm{MgCl}_{2}, 250 \mu \mathrm{M}$ of each dNTP and 1 unit of Taq DNA polymerase, $10 \times$ reaction buffer and $50 \mathrm{ng}$ of genomic DNA as template. The PCR conditions were $94^{\circ} \mathrm{C}$ for 5 min, followed by 35 cycles of $94^{\circ} \mathrm{C}$ for $40 \mathrm{~s}, 58^{\circ} \mathrm{C}$ and for $40 \mathrm{~s}$ and $72^{\circ} \mathrm{C}$ for $40 \mathrm{~s}$, with a final extension at $72^{\circ} \mathrm{C}$ for $5 \mathrm{~min}$. The product of the PCR was verified by $2 \%$ agarose gel electrophoresis and purified with Wizard Prep PCR purification kit (SolGent, Korea). The purified DNA fragments were directly sequenced in both directions using BigDye ${ }^{\mathrm{TM}}$ Terminator V3.1 Cycle Sequencing kit in an ABI 3130 genetic analyzer (Applied Biosystems, USA). Sequencer Software V5.1 (Applied Biosystems) was used to assemble the sequences and to identify polymorphisms. The Blast algorithm of NCBI was used to search the NCBI GenBank database (http://www.ncbi. nlm.nih.gov/) for homologous sequences. 


\section{SNP genotyping assay using PCR-RFLP}

Genotyping of the SNP located at position g.4271T $>\mathrm{C}$ (numbering according to GenBank database accession no. NC_007302.4) within intron 2 region of the NPY gene was performed by a PCR-RFLP method. For the PCRRFLP analysis, amplified fragments were digested with restriction enzyme $\operatorname{Hinf} \mathrm{I}$ at $37^{\circ} \mathrm{C}$ for at least $2 \mathrm{~h}$. The digested DNA fragments were separated on $2 \%$ agarose gel by electrophoresis with $1 \times$ TBE buffer. The gels were stained with ethidium bromide and the fragments were visualized using a UV transilluminator (Ultra Rum Inc, USA). To define each genotype according to band patterns, the PCR products of different RFLP type corresponding to each genotype were sequenced and analyzed for nucleotide changes.

\section{Statistical analysis}

Allele and genotype frequencies were calculated by simple allele counting method. Hardy-Weinberg equilibrium (HWE) in examined population was tested by comparing expected and observed genotype frequencies using a Chi-square test. The PROC GLM procedure of SAS (Release 9.2, SAS, Inst. Inc., USA) was used to test the association between SNP marker genotypes of the NPY gene and carcass and meat quality traits. The linear model used was as follows:

$$
Y_{i j k l m}=\mu+S_{i}+Y S_{j}+S P_{K}+A_{l}+G_{m}+e_{i j k l m}
$$

Where $Y_{i j k l m}$ is the observation of the carcass traits, $\mu$ is the overall mean for each trait, $\mathrm{S}_{i}$ is the effect of sire, $Y S_{i}$ is the effect of $\mathrm{i}_{\text {th }}$ year and season of calving, $S P_{k}$ is the effect of slaughter place, $A_{l}$ is the effect of age at slaughter (covariate), $G_{m}$ is the fixed effect of SNP genotype and $e_{i j k l m}$ is the random residual effect. Significant differences among mean values of different genotypes were calculated using Duncan's multiple range test, and determined to be statistically significant at $p<0.05$.

The additive and dominance effects were also estimated using REG procedure of SAS version 9.2, where the additive effect was denoted as $-1,0$ and 1 for TT, TC and $\mathrm{CC}$, respectively, and the dominance effect was denoted as $1,-2$ and 1 for TT, TC and CC, respectively.

\section{Results}

\section{SNP identification in the NPY gene}

A primer set for target gene fragment of the NPY successfully amplified a single band with 711 bp (Fig. 1) and used for subsequent sequencing of the amplicons. PCR

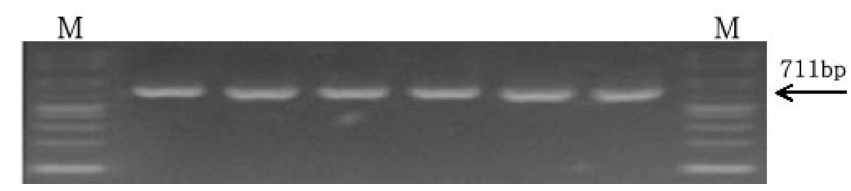

Fig. 1. Agarose gel electrophoresis to detect PCR amplified products (711 bp) of NPY gene in Hanwoo. M: 1001000 bp size marker

amplified products were the same as expected. For SNP detection of the NPY gene in Hanwoo, we amplified and sequenced intron 2 region of the NPY gene. Five SNPs were identified within intron 2 of the NPY gene, which were g.4389Del(C), g.4371Del(C), g.4271T $>$ C, g.1899A $>\mathrm{G}$ and g.1517A $>\mathrm{C}$ (Fig. 2). Among them, g4271T $>\mathrm{C}$ SNP was subjected to genotype the individuals of the population.

\section{SNP genotyping by using PCR-RFLP}

Genotyping of the SNP located at position g.4271T $>C$ within the intron 2 region of the NPY gene was performed by a PCR-RFLP method (Fig. 3). The genotype of g.4271T $>$ C SNP can be directly distinguished by the presence of PCR product, that is the presence of 701 and $10 \mathrm{bp}$ fragments represent $\mathrm{CC}$ homotype, the presence of 10, 295, and 406 bp represent TT homotype and the presence of all fragments are TC heterotype. However, the 10 bp fragments were not present on the gel because of very small size. The allele and genotype frequencies of the NPY gene estimated for the Hanwoo population are shown in Table 2. In the g.4271T $>$ C SNP, the frequency of allele $\mathrm{T}(68.4 \%)$ was higher than that of allele $\mathrm{C}$ $(31.6 \%)$. In the genotype frequencies, the homozygous genotype TT and heterozygous genotype TC showed higher frequency (46.6 and 43.7\%, respectively) compared to homozygous genotype CC $(9.7 \%)$, and these two genotypes TT and TC had similar frequencies. As shown in Table 2, the observed genotype distributions were in good agreement with those expected according to the HWE in this population.

\section{Association of gene-specific SNP marker with car- cass traits}

The effects of SNP genotype on the carcass and meat quality traits in Hanwoo were evaluated to clarify the relationship between the polymorphisms of NPY gene and these carcass traits. Results of the SNP markers association analysis are presented Table 3 . The SNP marker of g.4271T $>C$ was significantly associated $(p<0.027)$ with the LDA. Animals with the TT $\left(78.144 \pm 0.950 \mathrm{~cm}^{2}\right)$ gen- 


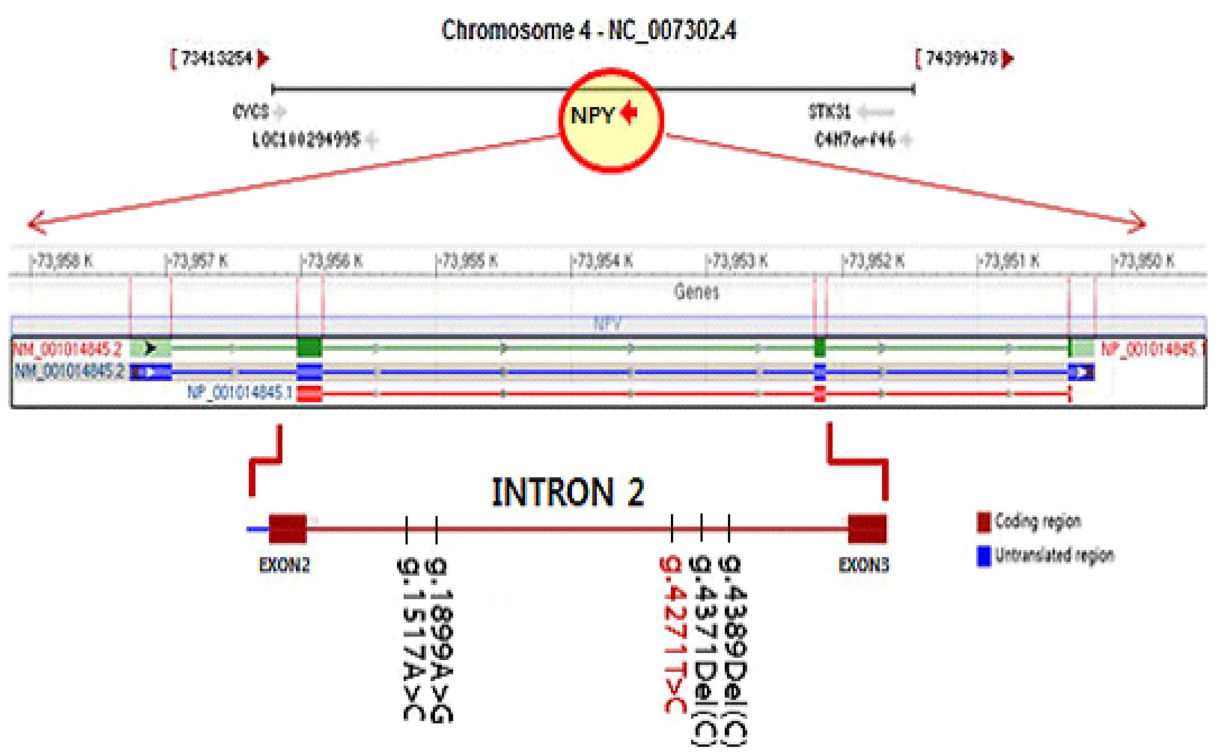

Fig. 2. Chromosomal location and SNP map of NPY gene in Hanwoo.

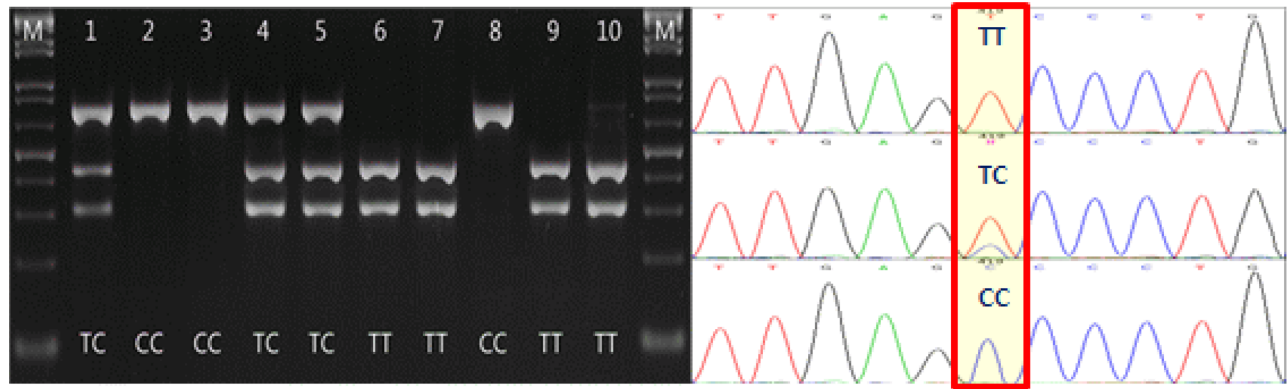

Fig. 3. PCR-RFLP analysis and sequence chromatograms for the detection of the different SNP genotypes of the NPY gene in Hanwoo. A SNP with the T $>$ C transition was detected at position 4271 within intron 2 region of the NPY gene. Lanes 2, 3 and 8 represent CC type. Lanes 1, 4 and 5 represent TC type. Lanes 6, 7, 9 and 10 represent TT type. M: 100-1000 bp size marker

Table 2. Genotype and allele frequencies for g.4271T $>$ C SNP within intron 2 region of the NPY gene in Hanwoo population

\begin{tabular}{|c|c|c|c|c|c|c|c|c|c|c|}
\hline \multirow{2}{*}{ SNP marker } & \multirow{2}{*}{$\begin{array}{c}\text { No. of } \\
\text { animals }\end{array}$} & \multicolumn{5}{|c|}{ Frequencies (\%) } & \multirow{2}{*}{$\mathrm{He}$} & \multirow{2}{*}{ PIC } & \multicolumn{2}{|c|}{ "HWE } \\
\hline & & \multicolumn{3}{|c|}{ Genotype } & \multicolumn{2}{|c|}{ Allele } & & & $\chi^{2}$ & $p$-value \\
\hline \multirow{2}{*}{ g. $4271 \mathrm{~T}>\mathrm{C}$} & \multirow{2}{*}{309} & TT & $\mathrm{TC}$ & $\mathrm{CC}$ & $\mathrm{T}$ & $\mathrm{C}$ & \multirow{2}{*}{0.582} & \multirow{2}{*}{0.491} & \multirow{2}{*}{0.043} & \multirow[b]{2}{*}{0.978} \\
\hline & & 46.6 & 43.7 & 9.7 & 68.4 & 31.6 & & & & \\
\hline
\end{tabular}

He, heterozygosity; PIC, polymorphic information content; HWE, Hardy-Weinberg equilibrium

Table 3. Association analysis between the different g.4271T $>$ C SNP genotype of NPY gene and carcass and meat quality traits in Hanwoo population

\begin{tabular}{|c|c|c|c|c|c|c|}
\hline \multirow{2}{*}{ Traits } & \multicolumn{3}{|c|}{ SNP genotype } & \multirow{2}{*}{ P-value } & \multicolumn{2}{|c|}{ Genetic effect } \\
\hline & $\mathrm{T} / \mathrm{T}$ & $\mathrm{T} / \mathrm{C}$ & $\mathrm{C} / \mathrm{C}$ & & Additive & Dominance \\
\hline $\mathrm{LW} / \mathrm{kg}$ & $549.275 \pm 5.971$ & $545.757 \pm 6.105$ & $528.000 \pm 12.807$ & 0.324 & $-21.275 \pm 14.131$ & $-14.239 \pm 18.677$ \\
\hline $\mathrm{CW} / \mathrm{kg}$ & $316.188 \pm 3.711$ & $313.030 \pm 3.794$ & $300.266 \pm 7.959$ & 0.196 & $-15.921 \pm 8.781$ & $-9.605 \pm 11.606$ \\
\hline $\mathrm{BF} / \mathrm{cm}$ & $0.761 \pm 0.035$ & $0.721 \pm 0.036$ & $0.753 \pm 0.075$ & 0.722 & $-0.008 \pm 0.083$ & $0.071 \pm 0.110$ \\
\hline $\mathrm{LDA} / \mathrm{cm}^{2}$ & $78.144 \pm 0.950^{\mathrm{a}}$ & $76.121 \pm 0.972^{\mathrm{ab}}$ & $72.266 \pm 2.039^{b}$ & $0.027^{*}$ & $-5.878 \pm 2.250^{* *}$ & $-1.830 \pm 2.973$ \\
\hline $\mathrm{MS} / 1 \sim 7$ & $2.866 \pm 0.432$ & $3.121 \pm 0.206$ & $3.132 \pm 0.203$ & 0.849 & $-0.265 \pm 0.478$ & $-0.243 \pm 0.631$ \\
\hline $\mathrm{MC} / 1 \sim 7$ & $5.000 \pm 0.116$ & $4.787 \pm 0.055$ & $4.808 \pm 0.054$ & 0.252 & $0.191 \pm 0.128$ & $0.233 \pm 0.169$ \\
\hline $\mathrm{FC} / 1 \sim 7$ & $3.000 \pm 0.021$ & $3.000 \pm 0.010$ & $2.985 \pm 0.009$ & 0.554 & $0.014 \pm 0.023$ & $-0.014 \pm 0.030$ \\
\hline $\mathrm{TEX} / 1 \sim 3$ & $1.466 \pm 0.229$ & $1.681 \pm 0.109$ & $1.735 \pm 0.107$ & 0.571 & $-0.268 \pm 0.253$ & $-0.161 \pm 0.334$ \\
\hline
\end{tabular}

LW, live weight; CW, carcass weight; BF, backfat thickness; LDA, M. Longissimus dorsi area; MS, marbling score; MC, meat color; FC, fat color; TEX, texture

*Effect was significant at $p<0.05 ; * *$ Effect was significant at $p<0.01$.

${ }^{\mathrm{a}, \mathrm{b}}$ Within a row, means with different superscript letter differ $(p<0.05)$. 
otype had higher LDA than those with the CC (72.266 $2.039 \mathrm{~cm}^{2}$ ) and animals with TC genotype showed intermediate value. This SNP genotype also showed a highly significant additive genetic effect for the LDA $(p<0.01)$. No significant associations, however, was detected between any of the SNP genotype and other carcass traits measured in this study.

\section{Discussion}

Carcass and meat quality traits, which are under the control of multiple genes, are economically important traits in beef cattle. Selection of animals with higher beef quality and better carcass composition is of great significance to farmers and consumers. Recent development in genomic analysis have made it possible to identify specific gene or gene markers that influence economic traits including carcass and meat quality traits in livestock. Although many meat quality traits have generally been assumed to be under the control of multiple genes, there is considerable evidence that single genes account for a relatively large amount of variation for some traits (Burrow et al., 2001; Warner et al., 2010). Therefore, gene markers that are significantly associated with certain traits of interest are very useful by applying DNA markers through marker-assisted selection. To date, several DNA markers of candidate gene associated with beef quality have been extensively described in the scientific literature. Moreover, the DNA marker discovery of the Australian CSIRO served as the IP for Genetic Solutions Pty. Ltd., which currently commercializes tests for a SNP in the 5' UTR of thyroglobulin (TG5) gene for its association with marbling and SNPs within calpastatin (CAST) and calcium activated neutral protease (CAPN1) for their associations with tenderness under the GeneStar trademark (Sosnicki and Newman, 2010).

In this study, we have selected NPY as a biological and physiological candidate marker gene and tested whether this gene showed an association with carcass and meat quality traits in Hanwoo population. It is one of the most potent orexigenic factors that is implicated in the control of feeding behavior and energy homeostasis (Zhang et al., 2011) and is one of the mediators of leptin (Thue and Buchanan, 2004). These physiological properties support NPY as a strong candidate gene for evaluation of genetic variations that could affect growth and carcass traits in beef cattle. Bovine NPY gene is located on chromosome 4 and contains three exons and two introns (Arora and Anubhuti, 2006). Three SNPs within intron 2 of the bovine NPY gene, A/G SNP, A/C SNP and T/C SNP, have been previously identified (Sherman et al., 2008; Thue and Buchanan, 2004). These SNPs have also been evaluated for associations with growth, performance and feed efficiency in beef steers (Sherman et al., 2008). Association analysis indicated that the three SNPs showed significant effects on growth and body weight $(p<0.05)$ with heavier animals containing the A allele of SNP 1(A/G) and SNP 2(A/C) and the $\mathrm{C}$ allele of SNP 3(T/C) (Sherman et al., 2008). These SNPs also affect carcass merit. Sherman et al. (2008) observed a strongest effect for marbling with SNP $1(p=0.007)$ and a trend for these SNP to affect backfat $(p<0.1)$. The NPY SNP 2 also has been showed allele substitution effects for lean meat area $(p<0.1)$ (Sherman et al., 2008). In this study, we also found that association between NPY SNP marker and LDA value. Lean meat area (LMA) or LDA is one of the economically important traits that affect carcass quantity in beef cattle. Although the results of this study suggest that this gene marker influence meat quantity traits, the exact mechanisms of this genetic changes remain unclear because this SNP does not cause amino acid changes. It is possible that this affect the transcription of the gene, splicing, mRNA stability or even translation process (Sherman et al., 2008).

Another five novel SNPs, 38017C $>$ G), 34240C $>$ A, $34168 \mathrm{G}>\mathrm{A}, 32463 \mathrm{~A}>\mathrm{C}$ and $32302 \mathrm{C}>\mathrm{G}$, have been reported in four Chinese indigenous cattle breeds by Zhang et al. (2011). They found that $32463 \mathrm{~A}>\mathrm{C}$ SNP and $32302 \mathrm{C}>\mathrm{G}$ SNP of NPY gene were associated with growth traits such as body length and chest girth in Nanyang cattle aged 6, 12 and 18 mon $(p<0.05)$. These finding demonstrate that NPY gene is an excellent biological candidate gene for body weight, carcass traits or growth-related traits in livestock. Mizoshita et al. (2004) also reported QTL identified on BTA4 in the region of bovine NPY for marbling and lean meat area. Therefore, it is possible that these NPY SNPs are linked to these QTL (Zhang et al., 2011). In humans, T1128C SNP marker in the 5 ' region of NPY gene was reported to be associated with birth weight, increased BMI and serum total cholesterol levels (Ding et al., 2005: Karvonen et al., 2000; Zhang et al., 2011). Association studies cannot determine if the gene allele markers (SNPs and RFLPs) are responsible for the variation in a trait or whether it is due to a closely linked locus. However, there is good reason to believe that this gene would influence the carcass traits in cattle. It is likely that these SNPs are linked to the QTL, because the QTL have been identified near the NPY gene. However, 
it will be very important for these SNPs to be verified in other cattle population to confirm these associations before they can be applied to marker assisted selection (Sherman et al., 2008). In summary, the identified SNP in NPY gene could be used a useful molecular DNA marker for selection of meat quantity trait such as LDA in Hanwoo.

\section{Acknowledgement}

This study was supported by Sangji University Research Fund, 2009.

\section{References}

1. Arora, S. and Anubhuti. (2006) Role of neuropeptides in appetite regulation and obesity. Neuropeptides 40, 375-401.

2. Burrow, H. M., Moore, S. S., Johnston, D. J., Baredse, W., and Bindon, B. M. (2001) Quantitative and molecular genetic influences on properties of beef: A review. Aust. J. Exp. Agr. 41, 893-919.

3. Ding, B., Kull, B., Liu, Z., Mottagui-Tabar, S., Thonberg, H., Gu, H. F., Brookes, A. J., Grundemar, L., Karlsson, C., Hamsten,A., Arner, P., Ostenson, C. G., Efendic, S., Monne, M., Von Heijne, G., Eriksson, P., and Wahlestedt, C. (2005) Human neuropeptide Y signal peptide gain-of-function polymorphism is associated with increased body mass index: possible mode of function. Regul. Pept. 127, 45-53.

4. Dyer, C. J., Simmons, J. M., Matteri, R. L., and Keisler, D. H. (1997) Effects of an intravenous injection of NPY on leptin and NPY-Y1 receptor MRNA expression in ovine adipose tissue. Domest. Anim. Endocrinol. 14, 325-333.

5. Karvonen, M. K., Koulu, M., Pesonen, U., Uusitupa, M. I., Tammi, A., Viikari, J., Simell, O., and Ronnemaa, T. (2000)
Leucin 7 to proline 7 polymorphism in the preproneuropeptide $\mathrm{Y}$ is associated with birth weight and serum triglyceride concentration in preschool aged children. J. Clin. Edocrinol. Metab. 85, 1455-1460.

6. Miller, S. A., Dykes, D. D., and Polesky, H. F. (1988) A simple salting out procedure or extracting DNA from human nucleated cell. Nucleic Acids Res. 16, 1215.

7. Mizoshita, K., Watanabe, T., Hayashi, H., Kubota, C., Yamakuchi, H., Todoroki, J., and Sugimoto, Y. (2004) Quantitative trait loci analysis for growth and carcass traits in a half-sib family of purebred Japanese Black (Wagyu) cattle. $J$. Anim. Sci. 82, 3415-3420.

8. Sherman, E. L., Nkrumah, J. D., Murdoch, B. M., Li, C., Wang, Z., Fu, A., and Moore S. S. (2008) Polymorphisms and haplotypes in the bovine neuropeptide Y, growth hormone receptor, ghrelin, insulin-like growth factor 2 , and uncoupling proteins 2 and 3 genes and their associations with measures of growth, performance, feed efficiency, and carcass merit in beef cattle. J. Anim. Sci. 86, 1-16.

9. Sosnicki, A. A. and Newman, S. (2010) The support of meat value chains by genetic technologies. Meat Sci. 86, 129-137.

10. Thue, T. D. and Buchanan, F. C. (2004) Linkage mapping of NPY to bovine chromosome 4. Anim. Genet. 35, 145-264.

11. Van Rosum, C. T. M., Piji, H., Adan R. A. H., Hoebee, B., and Seidell, J. C. (2006) Polymorphisms in the NPY and AGRP genes and body fatness in Dutch adults. Int. J. Obes. 30, $1522-1528$.

12. Warner, R. D., Greenwood, P. L., Pethick, D. W., and Ferguson, D. M. (2010) Genetic and environmental effects on meat quality. Meat Sci. 86, 171-183.

13. Zhang, L., Zhang, A. L., Zhang, L. Z., Zhang, Q., Zhang, C. L., Lan, X. Y., and Chen, H. (2011) Association analysis between variants in bovine NPY gene and growth traits in Nanyang cattle (Bos taurus). Gen. Comp. Endocrinology 170, 189-192. 